Erratum

\title{
Erratum to "Comparative Evaluation of Osseointegrated Dental Implants Based on Platform-Switching Concept: Influence of Diameter, Length, Thread Shape, and In-Bone Positioning Depth on Stress-Based Performance"
}

\author{
Luigi Baggi, ${ }^{1,2}$ Michele Di Girolamo, ${ }^{2}$ Giuseppe Vairo, ${ }^{3}$ and Gianpaolo Sannino ${ }^{2}$ \\ ${ }^{1}$ Department of Social Dentistry and Gnathological Rehabilitation, National Institute for Health, \\ Migration and Poverty (INMP), Rome, Italy \\ ${ }^{2}$ Department of Clinical Sciences and Translational Medicine, School of Dentistry, University of Rome Tor Vergata, Rome, Italy \\ ${ }^{3}$ Department of Civil Engineering and Computer Science, DICII, University of Rome Tor Vergata, Rome, Italy \\ Correspondence should be addressed to Gianpaolo Sannino; gianpaolo.sannino@uniroma2.it \\ Received 4 November 2013; Accepted 11 November 2013; Published 29 January 2014 \\ Copyright (C) 2014 Luigi Baggi et al. This is an open access article distributed under the Creative Commons Attribution License, \\ which permits unrestricted use, distribution, and reproduction in any medium, provided the original work is properly cited.
}

In the paper the list of authors was incomplete. As a mere management drawback, two coauthors (Luigi Baggi and Michele Di Girolamo) were missing from the paper. They have greatly contributed to the conception of the scientific framework that is posed within the paper, and they have widely contributed to the novel results proposed in the paper. They also oversaw the whole paper. The corrected list, order, and affiliations of authors are indicated in this erratum. 


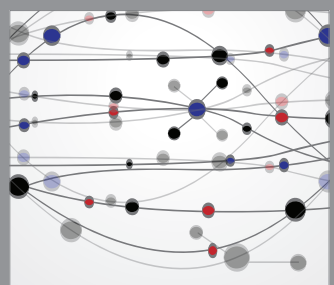

The Scientific World Journal
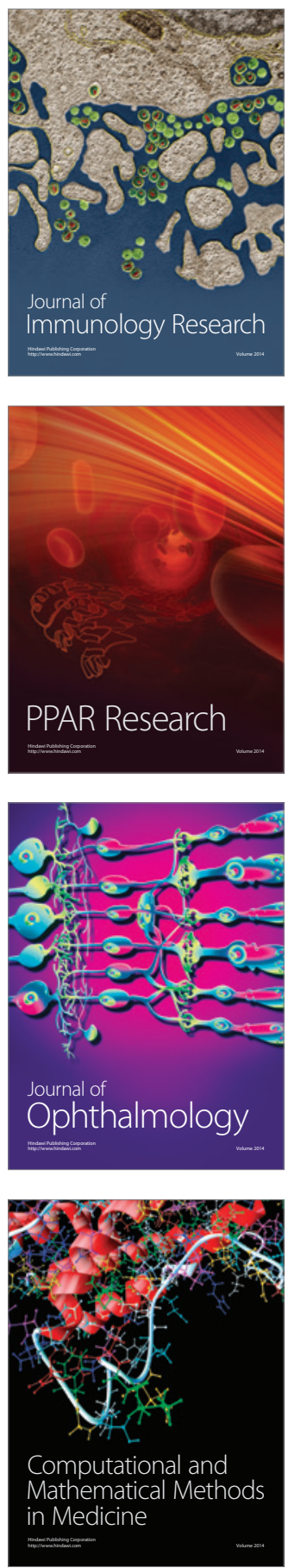

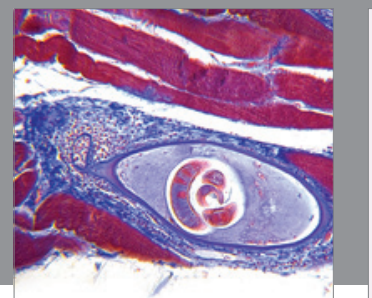

Gastroenterology

Research and Practice
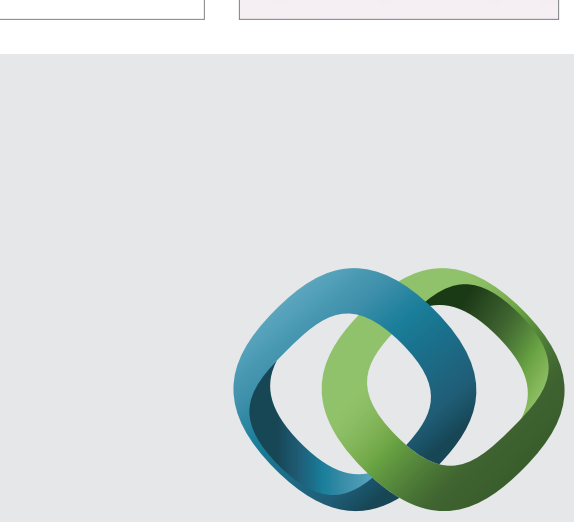

\section{Hindawi}

Submit your manuscripts at

http://www.hindawi.com
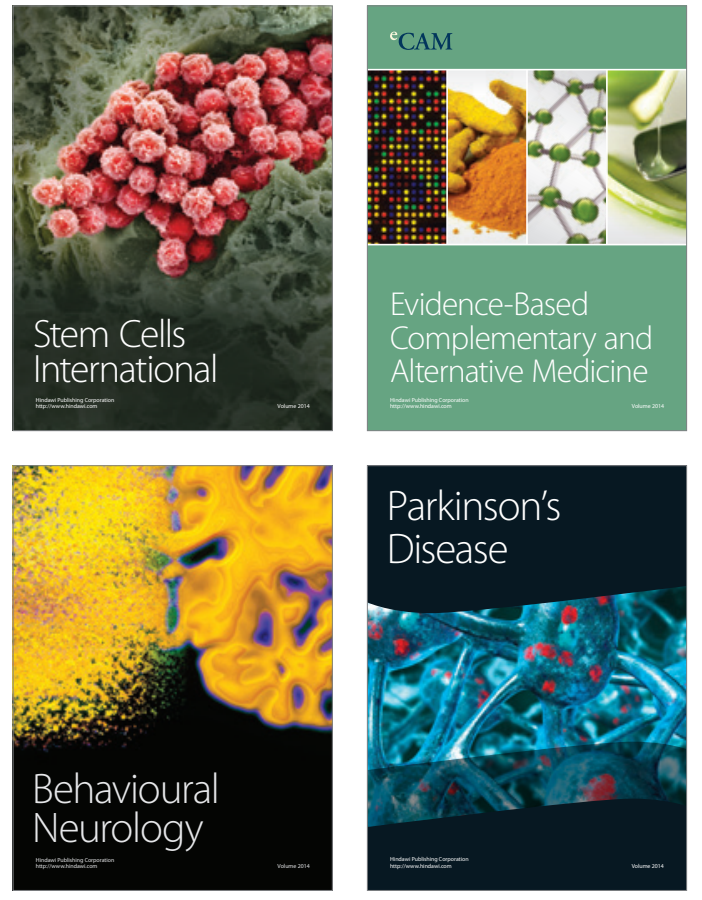
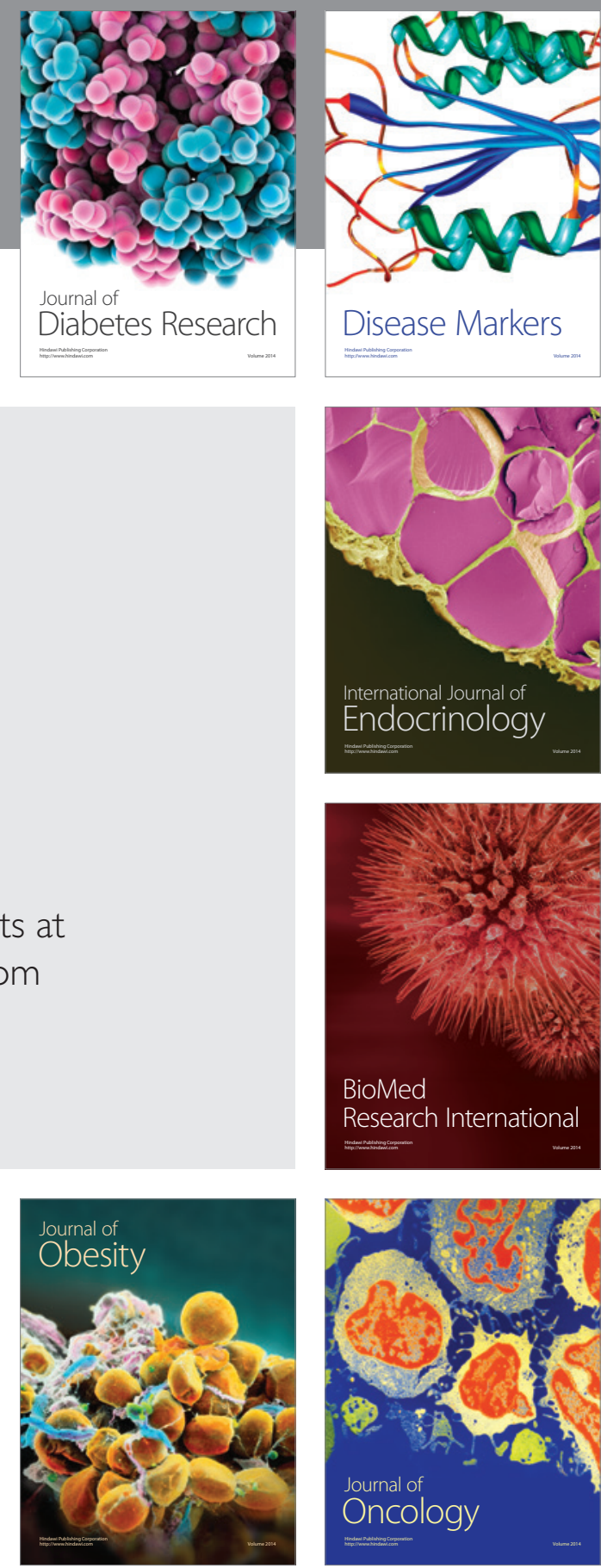

Disease Markers
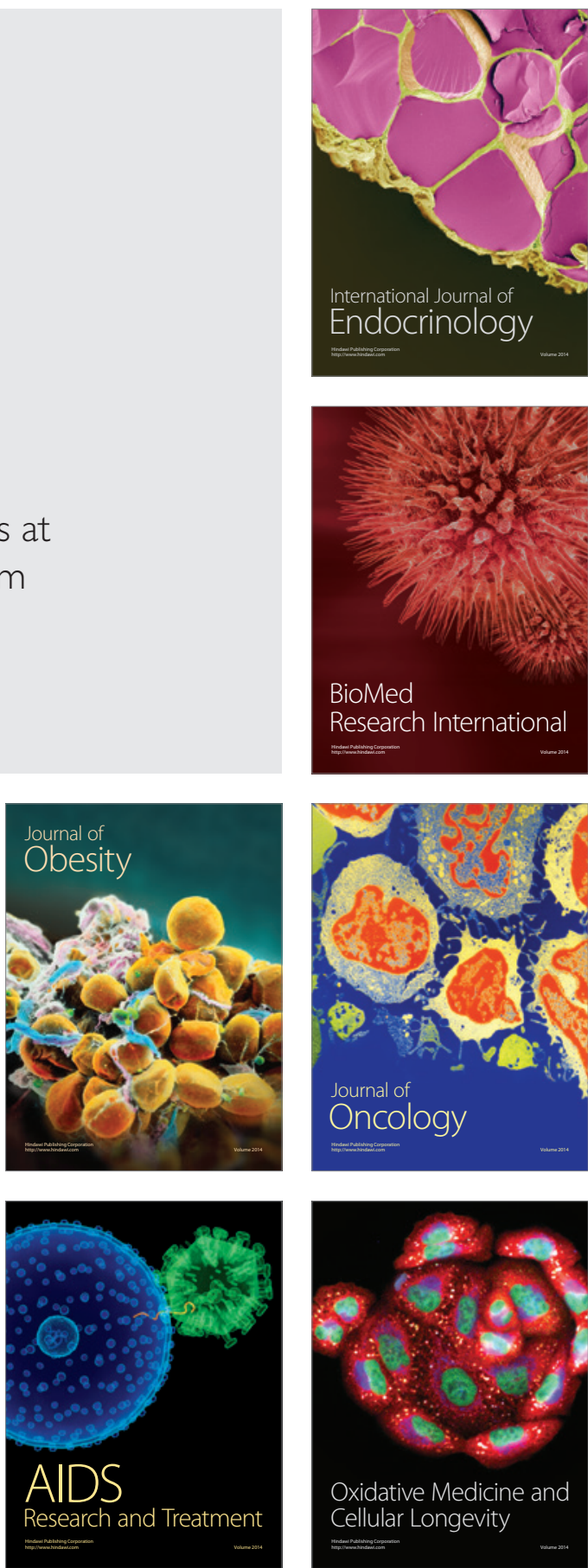